\title{
Intramedullary spinal cord tumor resection
}

\author{
Mari L. Groves, M.D., ${ }^{1}$ Patricia L. Zadnik, B.A., ${ }^{1}$ Pablo F. Recinos, M.D.,${ }^{1,2}$ \\ Violette Renard Recinos, M.D., ${ }^{2}$ and George I. JALlo, M.D. ${ }^{1}$ \\ ${ }^{1}$ Department of Neurological Surgery, The Johns Hopkins Hospital, Baltimore, MD; and ${ }^{2}$ Department of Neuro- \\ surgery, Cleveland Clinic Foundation, Cleveland, $\mathrm{OH}$
}

The authors present a case of a 27 -year-old patient who presented with spastic gait and worsening difficulty walking over a 6 month period. Spinal MR imaging revealed a heterogeneously enhancing intramedullary spinal cord tumor (IMSCT) with associated syrinx in the cervical spine. The lesion was resected through posterior en bloc laminotomy, durotomy, and microscopic resection of the intramedullary component followed by laminoplasty reconstruction. Surgical resections with a goal of gross total resection can significantly improve overall survival and progression free survival in patients with low-grade IMSCT. The procedure is presented in an edited, high-definition format with accompanying narrative.

The video can be found here: http://youtu.be/Ui9bn82PtP8.

(http://thejns.org/doi/abs/10.3171/2012.V2.FOCUS12154)

KEY WORDS • intramedullary spinal cord tumor • diagnostic and operative techniques - astrocytoma • ependymoma • laminoplasty $\bullet$ video

Manuscript submitted May 1, 2012.

Accepted May 17, 2012.

Please include this information when citing this paper: DOI:

10.3171/2012.V2.FOCUS12154.

Address correspondence to: George I. Jallo. Harvey 811, 600

North Wolfe Street, Baltimore, MD 21287. email: gjallo1@jhmi.edu. 